\title{
Ovarian Endometrioid Adenocarcinoma with Functioning Stroma Accompanied with Endometrial Endometrioid Adenocarcinoma: Immunohistochemical Study and Literature Review
}

\author{
Takashi Yuri $^{{ }^{*}}$, Tomomi Mizokami ${ }^{2}$, Yuichi Kinoshita ${ }^{1}$, Katsuhiko Yoshizawa ${ }^{1}$, Katsuhiko Yasuda $^{3}$, \\ Airo Tsubura ${ }^{1}$ \\ ${ }^{1}$ Department of Pathology II, Kansai Medical University, Divisions of Obsterics and Gynecology, Kansai Medical University, Osaka, \\ Japan; ${ }^{2}$ Hirakata Hospital, Osaka, Japan; ${ }^{3}$ Takii Hospital, Osaka, Japan. \\ Email: ${ }^{*}$ yurit@takii.kmu.ac.jp
}

Received May 20 ${ }^{\text {th }}, 2013$; revised June $20^{\text {th }}, 2013$; accepted July $20^{\text {th }}, 2013$

Copyright (C) 2013 Takashi Yuri et al. This is an open access article distributed under the Creative Commons Attribution License, which permits unrestricted use, distribution, and reproduction in any medium, provided the original work is properly cited.

\begin{abstract}
Background: The ovarian tumors with functioning stroma are defined by the morphological presence of endocrine active cells in stroma, and the clinical, biochemical or pathological evidence of endocrine function. Case Report: The ovarian endometrioid adenocarcinoma with functioning stroma accompanied with endometrial endometrioid adenocarcinoma was found in 64-year-old post-menopausal woman complaining abnormal genital bleeding and mammary distention. Her preoperative serum $17 \beta$-estradiol level was high $(53.2 \mathrm{pg} / \mathrm{ml})$ while human chorionic gonadotropin (hCG) level was within normal limit. Her right ovary with $8.8 \times 5.3 \mathrm{~cm}$ in size and tan-yellow in color mostly consisted of solid tumor. Histologically, tumor was composed of estrogen receptor (ER)- and progesterone receptor (PgR)-positive, and androgen receptor (AR)-negative cancerous endometrial cells with aggregates of vacuolated foamy stromal cells resembling luteinized cells. These stromal cells contained lipid droplets, and was immunopositive for $\alpha$-inhibin and $17 \beta$-estradiol. After surgery, serum $17 \beta$-estradiol level decreased and became normal (14.2 pg/ml). These findings indicate the production of steroid hormone (17 $\beta$-estradiol) from the foamy stromal cells and may be correlated with the clinical symptoms. Furthermore, ER- and PgR-positive endometrial endometrioid adenocarcinoma developed synchronously. However, ovary and uterus were totally immunonegative for human chorionic gonadotropin (hCG). Four other cases from the literature including ours are reviewed. Conclusion: Cancer cells were positive for ER and PgR in both ovary and uterus responded to steroid hormone produced by foamy stromal cells, which played a role in proliferation and progression of ovarian and endometrial endometrioid adenocarcinoma, respectively.
\end{abstract}

Keywords: Ovarian Cancer; Endometroid Adenocarcinoma; Functioning Stroma; Immunohistochemistry; Estrogen; Etradiol

\section{Introduction}

The majority of ovarian cancer patients are diagnosed at an advanced stage because clinical symptoms such as abdominal swelling or genital bleeding appears in late stage, and that no symptoms are evident in the early disease stage [1]. However, certain categories of ovarian tumors are capable of producing a variety of hormones that occasionally cause hormone-related symptoms on patients, which may suggest the occurrence of ovarian cancer. Hormonally functioning ovarian tumors are characterized

"Corresponding author. as those that secrete a variety of steroid hormones that may have unique clinical manifestation [2]. These ovarian tumors are defined as ovarian tumors with endocrine function. Such as the majority are of sex cord-stromal derivation. However, other tumors not usually associated with hormone secretion have also been implicated. Functioning ovarian tumors include not only sex cord-stromal tumors but also epithelial tumors with endocrine-functioning stromal cells. Some of ovarian epithelial tumors have luteinized stroma, and these stromal cells may possess hormonal activities [3,4]. Almost every type of ovarian primary and metastatic, benign and malignant 
tumors has been reported to cause both estrogenic and androgenic manifestation, but the most commonly encountered are primary ovarian mucinous tumor to have an estrogenic manifestation [5]. Whatever the oncogenic stimuli is, synchronous development of the same form of epithelial tumors in the ovary and endometrium is not a rare event [6-8].

As the frequency of endometrioid adenocarcinoma with functioning stroma is rare, we report herein an ovarian endometrioid adenocarcinoma with endocrinefunctioning stroma accompanied with endometrial endometrioid adenocarcinoma, which occurred in post-menopausal woman who complained abnormal genital bleeding and mammary distention for past 1 year. Our hypothesis was that human chorionic gonadotropin (hCG) may most probably stimulate $\alpha$-inhibin-positive stromal cells to luteinize and produce steroid hormone (17 $\beta$-estradiol) [9], then the produced hormone may transform cells positive for receptors (estrogen receptor, ER). The histological and immunohistochemical analysis together with literature review are reported.

\section{Case Report}

\subsection{Clinical Summary}

A 64-year-old woman, 3 gravida and 2 para, has been complained of menses-like monthly abnormal genital bleeding and mammary distention for past 1 year, and visited the gynecological out-patient clinic. Her menarche was at 14 and menopause was at 49 years of age. She had no previous gynecologic problems and no medication with steroid hormones. Her body weight was $64.4 \mathrm{~kg}$ and did not present virilism or hirsutism. The intrapelvic solid mass sized $7-8 \mathrm{~cm}$ in diameter suggestive of right ovarian tumor was pointed out with no ascitic fluid pooling by the pelvic magnetic resonance imaging. Hypertrophic endometrium was observed by transvaginal ultrasonography, and endometrial cytology revealed the presence of complex endometrial hyperplasia. The malignant ovarian and endometrial tumor was speculated and consulted Kansai Medical University Takii hospital for tumor resection.

Prior to the surgery, the vaginal smear appeared to be estrogenized and atypical endometrial proliferation was detected by endometrial brushing cytology. Serum tumor markers CEA, CA19-9, and CA125 were within normal range. While serum $17 \beta$-estradiol level was elevated compared with her age $(53.2 \mathrm{pg} / \mathrm{ml}$, normal range in post-menopausal woman is below $18.0 \mathrm{pg} / \mathrm{ml}$ ), serum hCG level was within normal range. Total abdominal hysterectomy with bilateral salpigooophorectomy, partial omentectomy and pelvic lymphadenectomy was carried out. A large tumor of the right ovary was detected. No atypical cells were found in intraperitoneal washing cytology. After the surgery, the concentration of serum $17 \beta$-estradiol was decreased to normal post-menopausal level $(14.2 \mathrm{pg} / \mathrm{ml})$, and patient is well and had no recurrence or metastatic symptoms for 5 years.

\subsection{Gross Findings}

The right ovary measuring $8.8 \times 5.3 \mathrm{~cm}$ in size was completely replaced by neoplasia. The major part of the tumor was solid and lobulated with partial cystic lesions (Figure 1), and did not adherent to the surrounding tissues. Cut surface was smooth and was tan-yellow in color with thin fibrotic septa. Hemorrhagic or necrotic lesions were not seen in any part of the tumor. The macroscopic findings of uterus and contralateral adnexa were normal, and metastatic nodules were not detected in resected tissues.

\subsection{Histological and Immunohistochemical Features}

Ten paraffin-embedded blocks were made from right ovary. Ovarian tumor was composed of epithelial proliferation with dense stroma (Figure 2(a)). Irregularly formed glands, papillary and columnar in configuration with enlarged nucleoli, were composed of tall columnar cells resembling endometrial gland (Figure 2(b)). Secretory products were apparent within the lumen of epithelial cells, and periodic acid-Schiff staining revealed mucin production in the lumen of irregular glands. Squamous differentiation of columnar epithelium was inconspicuous. The tumor was diagnosed as well differentiated ovarian endometrioid adenocarcinoma. Characteristically, aggregates of plump cells with foamy vacuolated cytoplasm were scatteredly seen in the stroma. Scattered nests of vacuolated cells resembled luteinized theca cells by the cytological features (Figure 2(c)), which oil red-O staining showed droplets of intracytoplasmic lipid (Fig-

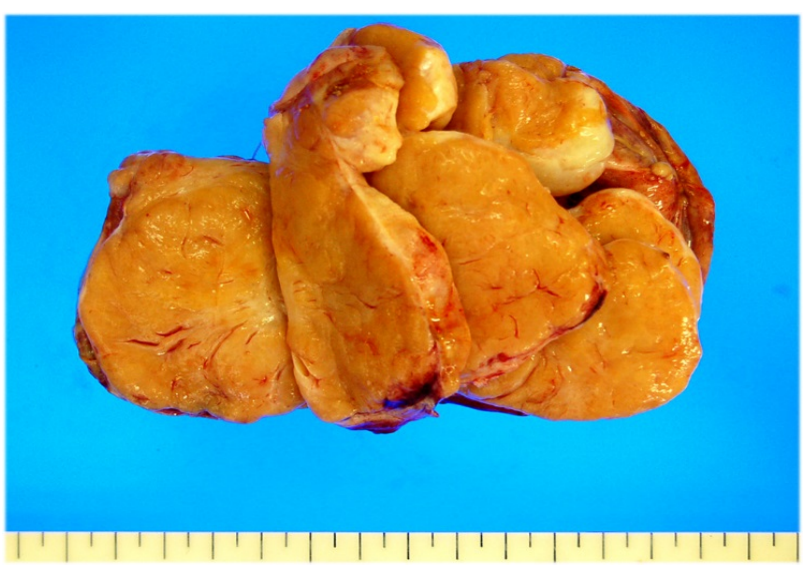

Figure 1. Resected ovarian tumor before the fixation. Tumor totally replaced the ovary, and was tan-yellow in color. 


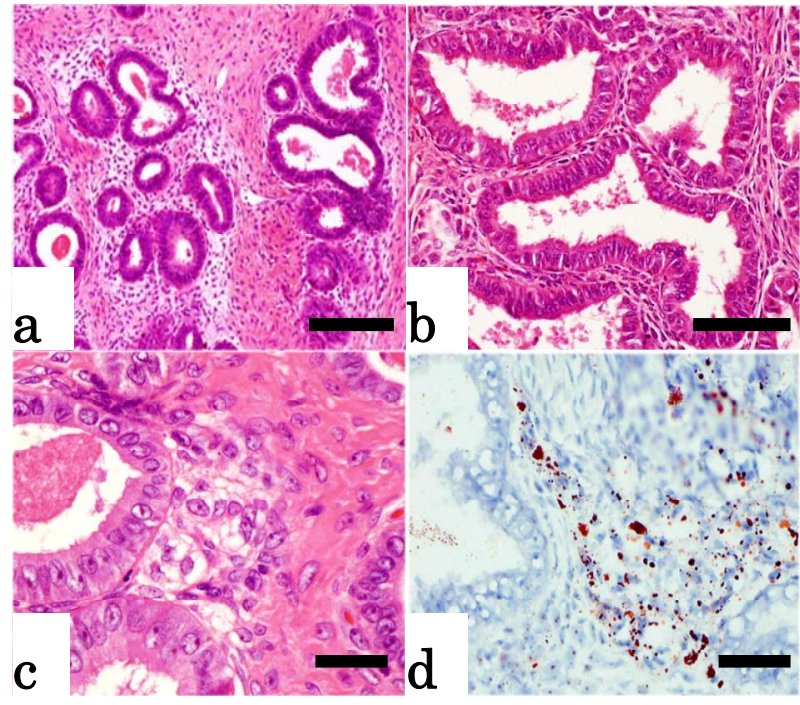

Figure 2. Histology of ovarian tumor. (a) (b) Well-differentiated endometrioid adenocarcinoma (HE); (c) Note clusters of vacuolated foamy cells that resemble to luteinized theca cells in the stroma (HE); (d) Stromal foamy cells contain droplet positive for oil red-O (oil red-O). Bars; (a) and (b) $=$ $100 \mu \mathrm{m}$, and (c) and (d) $=25 \mu \mathrm{m}$.

ure 2(d)). In addition to ovarian tumor, a single microscopic lesion consisted of well differentiated endometrial endometrioid adenocarcinoma at the fundus was detected (IB; slight invasion to myometrium without vessel involvement); noncancerous endometrium revealed not atrophic but proliferative phase-like endometrium. Although it was difficult not to declare the evidence of ovarian cancer metastasis to the uterus, because the right fallopian tube was free of cancer cells, no evidence of intrapelvic lymph node metastasis, and uterine cancer was composed of single microscopic lesion, we concluded that ovary and uterus developed separately (right ovarian endometrioid adenocarcinoma, pT1a and endometrial endometrioid adenocarcinoma, pT1a).

Antibodies used for immunohistochemcal analysis and staining results of ovarian and endometrial tumors are summarized in Table 1. Dilution and antigen retrievals were followed by manufacturer's instructions. Cytokeratins reacted with epithelial cells while vimentin reacts with stromal messenchymal cells. Vacuolated stromal cells seen in the ovary was immunoreactive with $\alpha$-inhibin (Figure 3(a)) and 17 $\beta$-estradiol (Figure 3(b)) as well as vimentin. Carcinoma cells in the ovary and endometrium were positive for ER (Figure 3(c)) and progesteron receptor (PgR), while androgen receptor (AR; Figure 3(d)) was negative. Within the tissue sections examined, $\beta$-hCG-positive cells were not detected in either tumor components, while luteinizing hormone/chorionic gonadotropin receptor (LHCGR) was positive in the cytoplasm of both uterine and ovarian adenocarcinoma cells

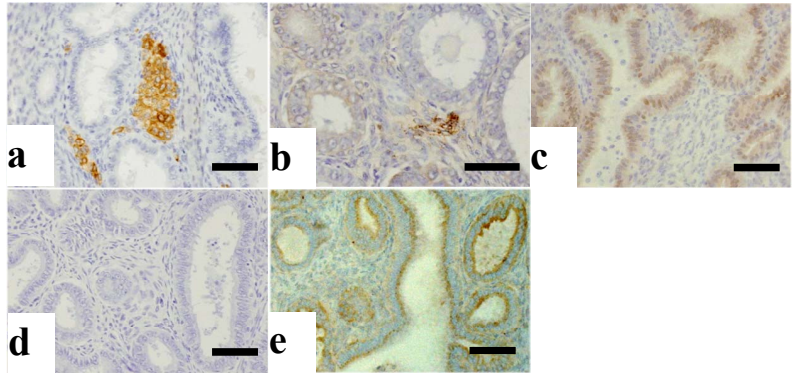

Figure 3. Immunohistochemistry of ovarian tumor. (a) $\alpha$-inhibin intensely labels luteinized stromal cells ( $\alpha$-inhibin), (b) $17 \beta$-estradiol is localized in luternized cells $(17 \beta$-estradiol), (c) Endometrioid adenocarcinoma cells are ER positive (ER); (d) No hCG positivity is seen in tumor section (hCG); (e) Endometrioid adenocarcinoma cells express LHCGR in the cytoplasm (LHCGR). Bars $=50 \mu \mathrm{m}$.

(Figure 3(e)).

\section{Discussion}

A variety of ovarian tumors, primary and metastatic, have been reported to be associated with functioning stroma; this association is more common in malignant tumor than in benign ones [9]. To reveal an estrogenic manifestation, ovarian mucinous tumor is most frequent [5]. The definitions of attributing origin of the hormonal alterations to the ovarian tumor are 1) the disappearance of hormonal manifestations after the tumor removal, and 2) histochemical detection of lipids in stromal cell cytoplasms [4]. In the present study, following removal of the ovarian tumor, a marked decrease in the plasma concentration of $17 \beta$-estradiol was observed. Common appearance of ovarian endometrial carcinoma represents solid nodule or including cystic lesions which may contain chocolate-colored fluids or mucin [10]. Lipid-rich tan yellowish-colored cut surface are macroscopical characteristics of theca cell tumor or hyperplasia. Ovarian hyperthecosis contains lipid-containing cells morphologically identical to the ovarian theca cells [11]. $\alpha$-Inhibin, a glycoprotein hormone that is produced by ovarian granulosa cells and testicular Sertoli cells usually immunoreacts with cells comprised of sex cord-stromal cells such as granulosa cells and theca cells in the ovary [12]; it intensely labels luteinized theca cells [13]. In our case, $\alpha$-inhibin reacted with clusters of stromal vacuolated cells, ovarian tumor was tan-yellow in color grossly and contained oil-red-O-positive lipids in the $\alpha$-inhibin-positive foamy stromal cells. Ovarian stromal hyperplasia and hyperthecosis is known to be associated with estrogenic and androgenic stimulation, and are considered to be the origin of excessive steroid hormones in the circulation [5,14]. Main source of the excess steroid hormones in ovarian stromal hyperthecosis can be proven from the 
Ovarian Endometrioid Adenocarcinoma with Functioning Stroma Accompanied with Endometrial

Endometrioid Adenocarcinoma; Immunohistochemical Study and Literature Review

Table 1. Immunohistochemisry of ovarian and endometrial endometrioid adenocarcinoma.

\begin{tabular}{|c|c|c|c|c|c|c|c|}
\hline \multirow{2}{*}{ Antibody } & \multirow{2}{*}{ Clone } & \multirow{2}{*}{ Source } & \multirow{2}{*}{ Dillution } & \multicolumn{2}{|c|}{ Ovarian tumor } & \multicolumn{2}{|c|}{ Endometrial tumor } \\
\hline & & & & Cancer cells & Stromal cells & Cancer cells & Stromal cells \\
\hline Cytokeratin & AE1/AE3 & Nichirei & Predilluted & + & - & + & - \\
\hline CK7 & OV-TL & Nichirei & Predilluted & + & - & + & - \\
\hline CK20 & Ks 20.8 & Nichirei & Predilluted & - & - & - & - \\
\hline Vimentin & V9 & Nichirei & Predilluted & - & + & - & + \\
\hline$\alpha$-Inhibin & R1 & DAKO & $\times 100$ & - & + & - & - \\
\hline CEA & COL-1 & Nichirei & Predilluted & - & - & - & - \\
\hline $17 \beta$-Estradiol & Polyclonal & Merck Millipore & $\times 150$ & - & + & - & - \\
\hline ER & $6 \mathrm{~F} 11$ & Novocastra & $\times 40$ & + & - & + & + \\
\hline $\operatorname{PgR}$ & 10A9 & Biodesign & $\times 50$ & + & - & + & - \\
\hline $\mathrm{AR}$ & AR27 & Novocastra & $\times 50$ & - & - & - & - \\
\hline$\beta$-hCG & CG04.05 & Neo Markers & $\times 100$ & - & - & - & - \\
\hline LHCGR & Polyclonal & Santa Cruz & $\times 200$ & + & - & + & - \\
\hline
\end{tabular}

Abbreviations: CEA, carcinoembryonic antigen; ER, estrogen receptor; PgR, progesterone receptor; AR, androgen receptor; $\beta$-hCG; $\beta$-Human chorinic gondotropin; LHCGR, Luteinizing hormone chorionic gonadotropin receptor.

marked decrease in the plasma levels of steroid hormones after ovarian wedge resection or oophorectomy [15]. The source of excess steroid hormones is considered to be produced by the luteinized cells present in the ovarian stroma [16-18]. We have localized $17 \beta$-estradiol in foamy cells in the ovarian stroma. Taken together, we diagnosed this ovarian tumor as endometrioid adenocarcinoma with $17 \beta$-estradiol secreting stromal cells from histological, histochemical, and clinical aspects.

hCG may act as a mitogen and most probably stimulates the stromal cells to luteinize and to produce steroid hormones estrogen, progesterone, or androgen [4]. Tumor containing syncytiotrophoblastic cells and patient during pregnancy is responsible to luteinize the stromal cells via hCG action. However, stromal luteinization is seen in patient who is not pregnant, and whose tumor which do not contain syncytiotrophoblast [9]. Some study suggest that tumor cells derived from ovarian epithelial cells produce $\mathrm{hCG}$ and cause the luteinization of stroma $[3,17,19]$. Another study suggests that epithelial ovarian cancer cells can produce $17 \beta$-estradiol by itself through interactions between cancer cells and luteinized stromal cells [20]. As the present ovarian tumor was totally negative with hCG, the explanation for the stromal cell stimulator and the mitogen for estrogen secretion needs further study. Although hCG levels were within normal levels and could not immunohistochemically localize hCG in the ovary, luteinized cells are postulated to be responsive to even normal levels of serum hCG [4]. It was note- worthy that LHCGR was present in ovarian and uterine endometrioid adenocarcinoma cells that carcinoma cells may mediate hCG or hCG-like signals to cause luteinization of the stromal cells to secrete $17 \beta$-estradiol. Then, estradiol may bind to the endometrioid adenocarcinoma cells positive for ER to promote the cancer cell proliferation. Estrogen secreting stromal cells may play a role in proliferation and progression of both ovarian and uterine adenocarcinoma cells.

Whatever the oncogenic stimuli, synchronous development of same form of epithelial tumors in the endometrium and ovaries is not a rare event [6-8]. Hyperestrogenic status plays an essential part in the origin of endometrioid adenocarcinoma. The histologically similar carcinoma in the endometrium and ovary may indicate either metastatic or independently developing neoplasms. Using microsatellite analysis, the loss of heterozygosity provides the difference in origin between the two tumors [6]. In the present case, histological subtype, degree of differentiation, immunore activities which we examined were similar between ovarian and endometrial carcinoma. The difficulty in the discrimination of the endometrial metastasis of ovarian carcinoma include the discrepancy in tumor sizes, the lack of multiple lesions often seen in metastatic site, and evidence of transtubal spread [7]. In our case, only one fundic lesion was found, the regional lymph nodes as well as fallopian ducts were free of tumor cells, and the discrepancy in size of each tumors $(8.8 \times 5.3 \mathrm{~cm}$-sized ovarian timor vs. endometrial lesion 
Table 2. Cases of ovarian endometrioid adenocarcinoma with functioning stroma.

\begin{tabular}{|c|c|c|c|c|c|c|c|c|c|}
\hline \multirow{2}{*}{ Case } & \multirow{2}{*}{$\begin{array}{l}\text { Age } \\
\text { (yr) }\end{array}$} & \multicolumn{2}{|c|}{ Serum estradiol (pg/ml) } & \multirow{2}{*}{-Tumor size $(\mathrm{cm})$} & \multirow{2}{*}{ FIGO staging } & \multirow{2}{*}{$\begin{array}{l}\text { Endometrial } \\
\text { lesion }^{\mathrm{a}}\end{array}$} & \multirow{2}{*}{ Treatment $^{b}$} & \multirow{2}{*}{$\begin{array}{c}\text { Follow up } \\
\text { (Disease free yrs) }\end{array}$} & \multirow{2}{*}{ Reference } \\
\hline & & Pre-surgery & Post-surgery & & & & & & \\
\hline 1 & 31 & 553 & Decreased & 12 & I a & $\mathrm{EC}, \mathrm{G} 2$ & 1 & 3 & [6] \\
\hline 2 & 69 & 22.8 & 10 & $7 \times 6$ & III b & $\mathrm{PA}$ & 1,2 & 1.25 & [16] \\
\hline 3 & 81 & 83 & Undetectable $(<10)$ & $12 \times 10$ & Ic (a) & $\mathrm{PA}$ & 1 & 1 & [20] \\
\hline 4 & 70 & 162.4 & 11.6 & $10 \times 9$ & Ic (b) & $\mathrm{AEH}-\mathrm{C}$ & 1,2 & 2 & [21] \\
\hline 5 & 64 & 53.2 & 14.2 & $8.8 \times 5.3$ & Ia & $\mathrm{EC}, \mathrm{G} 1$ & 1,2 & 5 & Present case \\
\hline
\end{tabular}

${ }^{\mathrm{a}} \mathrm{PA}$, proliferative activity: AEH-C, atypicalendomelrial hyperplasia,complex; EC, endometrial carcinoma. ${ }^{\mathrm{b}} 1$ means total abdominal hysterectomy with bilateral salpigooophorectomy; 2 means platinum-based combined chemotherapy.

at the microscopic level). Therefore we concluded that the tumors in ovary and endometrium despite the similar morphological features, was different origin.

Among ovarian epithelial tumors with functioning stroma, mucinous tumors are most frequent [4]. To the best of our knowledge, well-documented literatures of ovarian endometroid adenocarcinoma with functioning stroma was found in only 4 cases; 5 cases including our present case are summarized in Table $2[6,16,20,21]$. Age distribution ranged from 31 to 81 , which the average was 63 years of age. Elevations of serum estradiol value were seen in all cases $(22.8-553 \mathrm{pg} / \mathrm{ml}$, mean 174.9 $\mathrm{pg} / \mathrm{ml}$ ), and which declined to the average ranges for patient's age after the tumor resection. Surgical tumor resection was the principle treatment of this ovarian neoplasm $(7-12 \mathrm{~cm}$ in the largest diameter, mean $10.0 \mathrm{~cm})$, adjuvant chemotherapy was added if the tumor extend outside the ovary. Endometrial proliferative lesions including malignancy were detected in all cases regardless of patient's age. Estrogen secretion from luteinized theca cells in postmenopausal ovary may promote the growth of endometrial adenocarcinoma. In previous reports, theca cell hyperplasia seen in post-menopausal women has a marked incidence of endometrial adenocarcinoma [22]. Ovarian endometrial tumors frequently resemble to sex cord-stromal tumors by morphology [23]. However, $\alpha$-inhibin is positive in luteinized stromal cells but negative in endometrioid adenocarcinoma cells [19]. In contrast, ER and $\mathrm{PgR}$ are frequently positive in endometrioid adenocarcinoma cells [24] while negative in luteinized stromal cells. These markers may be useful in differential diagnosis.

\section{Conclusion}

We reported a rare case of ovarian endometrioid adenocarcinoma with functioning foamy stromal cells accompanied with endometrial endometrioid adenocarcinoma. Immunohistochemistry revealed $\alpha$-inhibin and the production of sex steroid hormone ( $17 \beta$-estradiol) in foamy stromal cells, which may be related to the promotion and proliferation of ER-positive ovarian and endometrial endometrioid adenocarcinomas. Therefore endometrial examination is essential in patients suffering ovarian endometrioid adenocarcinoma with functioning stroma. Additional cases are required to elucidate the precise mechanisms of this complication and to predict the patient's outcome.

\section{Acknowledgements}

The authors thank Ms. T. Akamatsu for her technical assistance of immunohistochemical assistance and Ms. A. Shudo for preparing the manuscript.

\section{REFERENCES}

[1] K. Gajjar, G. Ogden, M. I. Mujahid and K. Razvi, "Symptoms and Risk Factors of Ovarian Cancer: A Survey in Primary Care," International Scholarly Research Network Obstetrics and Gynecology, 2012, Article ID: 754197.

[2] J. M. Morris, R. E. Scully, "Endocrine Pathology of the Ovary,” CV Mosby, St. Louis, 1958, pp. 131-139.

[3] J. L. Rutgers and R. E. Scully, "Functioning Ovarian Tumors with Peripheral Steroid Cell Proliferation; a Report of Twenty-Four Cases," International Journal of Gynecological Pathology, Vol. 5, No. 4, 1986, pp. 319-337. http://dx.doi.org/10.1097/00004347-198612000-00004

[4] F. A. Tavassoli, "Ovarian Tumors with Functioning Manifestations," Endocrine Pathology, Vol. 5, No. 3, 1994, pp. 137-148. http://dx.doi.org/10.1007/BF02921469

[5] Y. O. Tanaka, H. Tsunoda, Y. Kitagawa, T. Ueno, H. Yoshikawa and Y. Saida, "Functioning Ovarian Tumors: Direct and Indirect Findings at MR Imaging," Radiographics, Vol. 24, Suppl. 1, 2004, pp. S147-S166. http://dx.doi.org/10.1148/rg.24si045501

[6] N. Takai, K. Kai, A. Tsumo, K. Nasu, K. Kashima and H. Narahara, "Synchronous Ovarian Endometrioid Adenocarcinoma with a Functioning Stroma and Endometrial Endometrioid Adenocarcinoma by Different Loss of Heterozygosity Findings," Archives of Gynecology and Ob- 
sterics, Vol. 284, 2010, pp. 951-955

[7] T. M. Ulbright and L. M. Roth, "Metastatic and Independent Cancers of the Endometrium and Ovary: A Clinicopathologic Study of 34 Cases," Human Pathology, Vol. 16, No. 1, 1985, pp. 28-34.

http://dx.doi.org/10.1016/S0046-8177(85)80210-0

[8] C. C. van Niekerk, J. Bulten, G. P. Vooijs and A. L. Verbeek, "The Association between Primary Endometrioid Carcinoma of the Ovary and Synchronous Malignancy of the Endometrium," Obsterics and Gynecology Intenational, 2010, Article ID: 465162.

[9] R. E. Scully, R. H. Young and P. B. Clement, “AFIP Tumors with Functioning Stroma, Atlas of Tumor Pathology, 3rd Series, Tumors of the Ovary, Maldevelopment Gonads, Fallopian Tube, and Broad Ligament," Washington DC, 1998, pp. 373-378.

[10] R. E. Scully, R. H. Young and P. B. Clement, "AFIP Tumors with Functioning Stroma, Atlas of Tumor Pathology, 3rd Series, Tumors of the Ovary, Maldevelopment Gonads, Fallopian Tube, and Broad Ligament," Washington DC, 1998, pp. 107-128.

[11] M. Farber, P. R. Daoust and J. Rogers, "Hyperthecosis Syndrome," Obsterics and Gynecology, Vol. 44, 1974, pp. 35-41.

[12] T. J. Pelkey, H. F. Frierson Jr., S. E. Mills and M. H. Stoler, "The Diagnostic Utility of Inhibin Staining in Ovarian Neoplasms," International Journal of Gynecological Pathology, Vol. 17, No. 2, 1998, pp. 97-105. http://dx.doi.org/10.1097/00004347-199804000-00001

[13] C. R. Stewart, M. D. Jeffers and A. Kennedy, "Diagnostic Value of Inhibin Immunoreactivity in Ovarian Gonadal Stromal Tumours and Their Histological Mimics," Histopathology, Vol. 31, No. 1, 1997, pp. 67-74. http://dx.doi.org/10.1046/j.1365-2559.1997.5780819.x

[14] E. Kemmann, D. Orenstein, R. M. Shelden and J. R. Jones, "Estrogenization in Women with Postmenopausal Ovarian Hyperthecosis," International Journal of Gynaecology and Obsterics, Vol. 18, 1980, pp. 188-191.

[15] J. Aiman, C. D. Edman, F. R. Worley, F. Vellios and P. C. MacDonald, "Androgen and Estrogen Formation in Women with Ovarian Hyperthecosis," Obsterics and Gynecology, Vol. 51, 1978, pp. 1-9.

[16] Y. Kurihara, K. Kasahara, H. Sasano, Y. Tsutsumi, "Ovarian Endometrioid Adenocarcinoma Associated with Steroidogenic Foamy Stromal Cells," Pathology International, Vol. 47, No. 12, 1997, pp. 883-888. http://dx.doi.org/10.1111/j.1440-1827.1997.tb03722.x

[17] N. Antoniou, M. Varras, Ch. Akrivis, A. Demou, A. Bellou and S. Stefanaki, "Mucinous Cystadenoma of the Ovary with Functioning Stroma and Virilization in Pregnancy: A Case Report and Review of the Literature," Clinical and Experimental Obsterics and Gynecology, Vol. 30, 2003, pp. 248-252.

[18] F. Bolat, A. Parlakgumus, T. Canpolat and I. Tuncer, "Benign Mucinous Cystadenoma with Stromal Luteinization Responsible for Maternal Virilization and Fetal Intrauterine Growth Restriction," Journal of Obsterics and Gynaecology Research, Vol. 37, No. 7, 2011, pp. 893-896. http://dx.doi.org/10.1111/j.1447-0756.2010.01406.x

[19] X. Matias-Guiu and J. Prat, "Ovarian Tumors with Functioning Stroma. An Immunohistochemical Study of 100 Cases with Human Chorionic Gonadotropin Monoclonal and Polyclonal Antibodies," Cancer, Vol. 65, No. 9, 1990, pp. 2001-2005.

http://dx.doi.org/10.1002/1097-0142(19900501)65:9<200 1::AID-CNCR2820650920>3.0.CO;2-7

[20] H. Tokunaga, J. Akahira, T. Suzuki, T. Moriya, H. Sasano, K. Ito and N. Yaegashi, "Ovarian Epithelial Carcinoma with Estrogen-Producing Stroma," Pathology International, Vol. 57, No. 5, 2007, pp. 285-290. http://dx.doi.org/10.1111/j.1440-1827.2007.02099.x

[21] T. Hayasaka, K. Nakahara, T. Kojimahara, M. SaitoSekiguchi, T. Motoyama and H. Kurachi, "Endometrioid Adenocarcinoma with a Functioning Stroma," Journal of Obsterics and Gynaecology Research, Vol. 33, No. 3, 2007, pp. 381-383. http://dx.doi.org/10.1111/j.1447-0756.2007.00541.x

[22] R. Fienberg, "The Stromal Theca Cells and Postmenopausal Endometrial Adenocarcinoma," Cancer, Vol. 24, No. 1, 1969, pp. 32-37. http://dx.doi.org/10.1002/1097-0142(196907)24:1<32::AI D-CNCR2820240104>3.0.CO;2-I

[23] A. Misir and M. Sur, "Sertoliform Endometrioid Carcinoma of the Ovary. A Potential Diagnostic Pitfall," Archives of Pathology and Laboratory Medicine, Vol. 131, 2007, pp. 979-981.

[24] J. Ordi, D. P. Schammel, L. Rasekh and F. A. Tavassoli, "Sertoliform Endometrioid Carcinomas of the Ovary: A Clinicopathologic and Immunohistochemical Study of 13 Cases," Modern Pathology, Vol. 12, No. 10, 1999, pp. 933-940. 